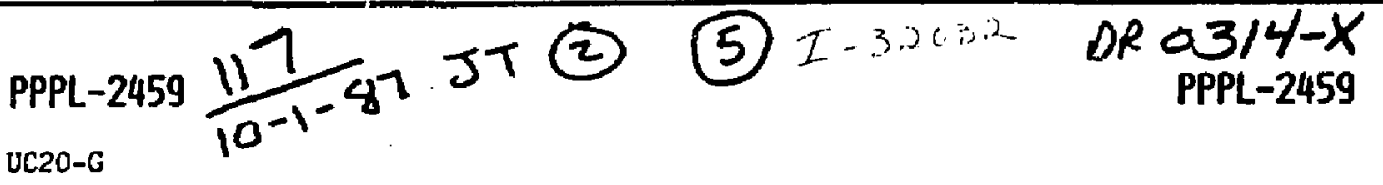

PPPL -2459

DE88 000116

RIGOROUS UPPER BOUNDS FOR FLUID AND PLASMA TRANSPORT DUE TO PASSIVE ADVECTION

By

J.A. Krommes, R.A. Smith, and C.-B. Kim

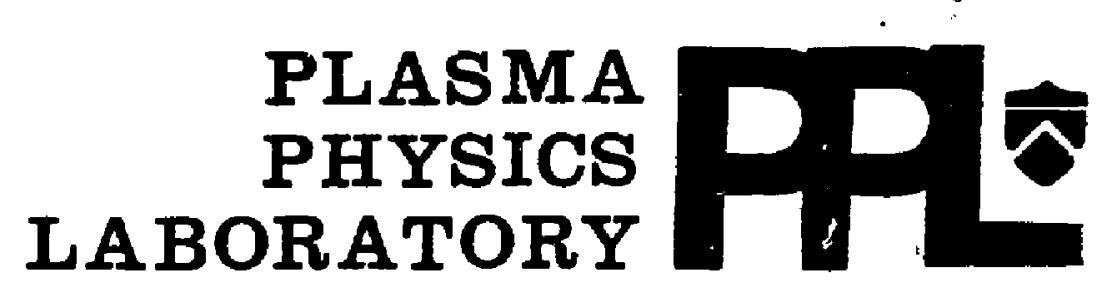

PRINCETON UNIVERSITY

PRINCETON, NEW JERSEY

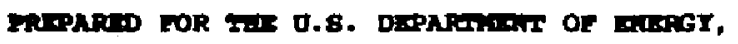

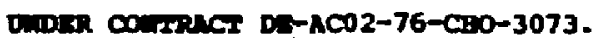

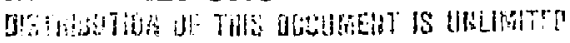


This report was prepared as an account of work sponsored by the United states Government. Weither the United states nor the United States Department of Energy, nor any of their employees, nor any of their contractors, subcontractors, or their employees, makes any warranty, express or implied, or assumes any legal liability or responsibllity for the accuracy, completeness or usefulness of any information, apparatus, product or process disclosed, or represejts that its use would not infringe pxivately owned rights.

Printed in the United States of America

Avallable from:

National Technical Information Service

U.S. Department of Commerce

5285 Port Royal Road

Springfield, Virginia 22161

Price Printed Copy $\$ \ldots$; Microfiche $\$ 4.50$

*Pages

$1-25$

25-50

$51-75$

$76-100$

101-125

$126-150$

$151-175$

$176-200$

$201-225$

$226-250$

$251-275$

$276-300$

$30 t-325$

$326-350$

$351-375$

$376-400$

401-425

426-450

$451-475$

476-500

$500-525$

$526-550$

$551-575$

$567-600$

NTIS

Selling Price

$\$ 7.00$

$\$ 8.50$

$\$ 10.00$

$\$ 11.50$

$\$ 13.00$

$\$ 14.50$

$\div 16.00$

$\$ 17.50$

$\$ 19.00$

$\$ 20.50$

$\$ 22.00$

$\$ 23.50$

$\$ 25.00$

$\$ 26.50$

$\$ 28.00$

$\$ 29.50$

$\$ 31.00$

$\$ 32.50$

$\$ 34.00$

$\$ 35.50$

$\$ 37.00$

$\$ 38.50$

$\$ 40.00$

54.50
For documents over 600 pages, add $\$ 1.50$ for each additional 25-page increment. 


\title{
Rigorous upper bounds for fluid and plasma transport due to passive advection
}

\author{
JOHN A. KROMMES \\ RALPH A. SNITH' \\ CHANG-BAE KIM \\ Princeton University, Plasma Physics Laboratory \\ P.O. Box 451, Princeton, NJ 08544-0451 USA
}

\begin{abstract}
The formulation of variational principles for transport due to passive advection is described. A detailed account of the work has been published elsewhere (Ars. Phys., 1987). In the present paper, the motivations, philosophy, and implications of the method are briefly discussed.
\end{abstract}

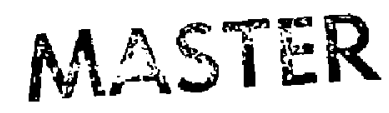

1 Present address: Dept. of Physics, University of California at San Ditgo, La Jolla, California 92093 USA. 


\section{INTRODUCTION}

It is a platitude that transpor due to fully developed turbulence, either in fluids or in plasmas, is a difficult theoretical problem. None of the methods based on statistical closures, including the direct-interaction approximation, ${ }^{1}$ has proven to be fully satisfactory. It is, therefore, of considerable interest that a formalism exists which provides rigorous results-in particular, rigorous bounds from above on the steady-state transport in situations in which the mean gradients are maintained by inhomogeneous boundary conditions. The mathematical method-a way of formulating certain variational principles-is due originally to Howard. ${ }^{2} \mathrm{He}$, in turn, was motivated by the earlier physical considerations of Malkus, ${ }^{3}$ who speculated that the physically realized state of thermal convection was the one which maximized the thermal flux through the system. Although this turns out to be false, except in certain limiting situations, it led Howard to ask the rigorous question "What is the maximum flux compatible with the equations of motion?" This can be answered using conventional techniques of variational calculus. The mathemat ical formalism and many of its physical consequences for fluids have been reviewed by Busse, ${ }^{4}$ who called the procedure the "optimum theory."

Fundamentally. the present work was motivated by our interest in certain plasma physics problems relevant, in particular, to magnetic confinement of fusion plasmas. We wanted to understand the implications of the optimum theory for problems involving drift wave turbulence, both electrostatic and electromagnetic. For physical reasons, one is interested primarily in self-consistent problems, in which the aduecting velocity is determined by the particle distribution function. However, recognizing that self-consistency is very difficult to study analytically, we decided to consider first the simplifying assumption of passive advection. Hro, the fluctuating $\boldsymbol{E} \times \boldsymbol{B}$ velocity and nagnetic field are assumad to be statistically specified, independent of the particle distribution. Certain physical situations have been previously couched in those terns-for example, the problem of particle and heat transport in given stochastic magnetic fields. ${ }^{e}$ However, we are motivated primarily by questions of pedagogy. The self-consistent variational formalism is generally algebraically complex, especially for complicated fluctuations such as drift waves. ${ }^{7}$ This complexity tends to obscure certain important conceptual issues, of particular importance for plasma problems. However, these issues persist in models of passive advection, which are more araenable to careful study and illustration. Thus, we have studied the general theory of the passive problem in some depth.

Our detailed studies of variational principles for passive advection have been published elsewhere. ${ }^{8}$ It seems pointless to repeat here the extensive discussion in that reference. Therefore, after summarizing the method very briefy, we shall merely review the important features of, and difficulties with, the method. Thus, this report can serve as a short beginners' guide to the lengthy analysis found in Ref. 8. 


\section{THE GENERAL PHILOSOPHY OF THE OPTIMUM THEORY}

The bounding method is based on the well-known observation that the statistical solution of a dynamical equation with random elements (either random initial conditions or random coefficients) is very dificult because the solution is infinitely constrained, either by a statistical moment hierarchy or, equivalently, by an infinite number of realizability constraints. ${ }^{9}$ One may feel intuitively that only low order constraints should be important physically; however, attempts to capture accurately the behavior of the low order moments with conventional statistical closure approximations have met with only limited suscess. (Witness, for example, the failure of the direct-interaction approximation to preserve random Gajilean invariance.) In the optimum theory, one deals with low order irformation more directly, by eschewing accuracy for rigor. By considering only one or a small number of moment constraints, rather than infinitely many, one is able to extract rigorous bounds from above on steady-state transport, at a manageable level of mathematical description. In princjple, a sequence of successively more constrained variational problems can be envisioned, such that in the limit of infinitely many constraints the true solution of the problem should be recovered. However, since this is clearly impractical, the question becomes just what physics is captured or omitted at the level of the lowest order bounds.

In Ref. 8 we called the lowest order bound the "basic" bound, and took it to be the steady-state globi ! nergy balance. Schematically, this balance has the form

$$
\mathcal{P}=\boldsymbol{T}+\mathcal{D}
$$

where $\mathcal{P}$ stands for "production" (the interaction of the fluctuations with the mean fields), $\tau$ stands for "transfer" (the conservative nonlinear coupling between various modes), and $\mathcal{D}$ stands for "dissipation" (due to classical effects). The optimum theory parts company with more conventional statistical closure approximations such as the direct-interaction approximation by the way it deals with the transfer term, which for quadratically nonlinear dynamical equations is the divergence of a triplet correlation function. In closure theory, ${ }^{10,11}$ the triplet correlation is expressed approximately in terms of two-point quantities (the covariance and the infinitesimal response function), giving a closed system of equations which can, in principie, be solved for the covariance and, hence, the steady-state transport. In contrast, in the optimum theory the solenoidal nature of the transfer term is exploited: the transfer term is annihilated by integrating Eq. (2.1) over the direction $x$ of inhomogeneity. (Typically, one assumes that the fluctuations vanish at the boundaries.) The resulting global balance,

$$
\overline{\mathrm{P}}=\overline{\mathcal{D}},
$$

provides an important constraint on the steady-state transport, and the basic variational principle is: Maximize the transport subject to the global balance constraint (2.2). For problems of passive advection, this single const raint can be shown to be sufficient to provide a well-posed mathematical problern. It can be included by the method of Lagrange multjpliers, or described equivaiently by a homogeneous minimum principle due to Howard. ${ }^{2,4,8}$ 


\section{ONE- AND TWO-TIME CONSTRAINTS}

In Ref. 8, the mechanics and accuracy of the basic method were illustrated by considering a :imple one-dimensional model problem, called the reference model, which cuuld be solved exactly. The problem was the passive advection of a scalar concentration, in the limit of infinite autocorrelation time for the advecting field but for arbitrary Reynolds number $R$. The basic bound was found to be approximately $25 \%$ too high in the worst case of infinite $R$. Since the problem is highly nonlinear in this limit. such a result is quite acceptable. Similar agreements have been found in more complicated applications. 12

Nevertheless, an important piece of physics is missing from the basic bound. That bound is constructed entirely from equal-time and equal-space currelation functions. It is impossible for such a theory to recognize properly the effects of finite autocorrelation times, either due directly to random temporal fluctuations in the advecting field or indirectly to spatial fluctuations combined with advection or strearning. This is quite clear in passive problems, where the autocorrelation time ${ }^{5}$ ac can be specified independently of the Reynolds number. In self-consistent probierns, where everything is coupled, $\tau_{\text {ac }}$ is not independent of $R$. Nevertheless, important aspects of the two-time correlations are overlooked by the basic bound. For passive problems, the basic bound behaves as though the autacorrelation time were infinity, even when that is not so physically. No such theory is capable of predicting quasilinear transport, for example. ${ }^{8}$

In order to improve the theory to capt ure such qualitative effects, one must introduce the notion of two-time constraints. This possibility was considered for the first time in Ref. 8. Clearly, a wide variety of two-time constraints are viable candidates, and very little is known about the choice of the optimal one. In Ref. 8 we demonstrated that for the reference model it was possible ta use one simple two-time constraint to determine a bound which, in addition to being rigorous, reasonably interpolated between the limit of very short autocorrelation time (quasilinear theory) and the opposite limit of very long autocorrelation time (strong turbulence). However, it was also clear that significant technical complications would be encountered when the technique was applied to practical problems. The situation is not unlike that with the direct-interaction approximation, which in its attempt to be faithful to the two-time dynamics introduces complicated time history integrals which are difficult to evaluate, even numerically, Research continues on the relative merits of the two-time optimum theory and the direct-interaction aporoximation. For many practical situations, there is reason to believe that the one-time bound may be reasonable. For example, one might attempt to argue this when the system is known to saturate at the boundary between the quasilinear and strong turbulence regines.

\section{RECENT RESULTS ABOUT THE OPTIMUM THEORY}

Recently we have been able to generalize several aspects of the discussion of two-time constraints in Ref. 8. First, the construction of the two-time constraint which was used 
there followed as closely as possible the construction of the basic constraint, in that the twotime triplet correlation was again annihilated by integrating a two-time moment equation in $x$ from 0 to 1 . This is not a necussity, however. In principle, the two-time triplet can be retained in the constraint. This leads to a substantially more complicated EulerLagrange equation. However, we have been able to show thai for the simple reference model an analytic solution of the Euler-Lagrange equation remains possible, and predicts an improved bound. It is clear, though, that the complication of carrying through such procedures for realistic problems with many variables is probably prohibitive.

A more physical question is how to generalize the manipulations of Ref. 8 to include effects due to finite spatial autocorrelation lengths of the advecting field. Such a situation arises in the case of static stochastic magnetic fields ${ }^{6}$ in the collisionless limit in which particles stream along the perturbed lines. That streaming is described by an operater $\left(\partial_{t}+v_{\mid} \cdot \dot{b}_{0} \cdot \nabla\right)$, where $\hat{b}_{0}$ describes the direction of the unpert urbed lines and is perpendicuiar to the $x$ direction. The fundamental difficulty with constructing a two-time and two-space constraint arises from the fact that for arbitrary $\boldsymbol{z}$ dependence the triplet tem involves both an $\boldsymbol{x}$ and an $\boldsymbol{x}^{\prime}$, so that one cannot replace the full divergence operator by $\partial / \partial \boldsymbol{x}$. Furthermore, a straightforward attempt to annihilate the triplet term by integrating over $x$, $y$, and $z$ fails because such an averaging completely removes the sireaming effect from the theory: $\int d y d z v_{l} \hat{b}_{0} \cdot \nabla \equiv 0$. We have not sought a general solution for this problem. However, an interesting physical limit is $\delta B_{z} \approx 0$. For this case one can annihilate the triplet term by integrating over only $x$ and $y$, which leaves the dominant part of the streaming term intact. We have carried through such a procedure in detail and verined that no untoward problems arise. Thus, we can now give rigorous upper bounds for the collisionless regime of static stochastic magnetic fields which embrace both the quasilinear and the strong turbulence regimes. This work will be reported in detail elsewhere.

\section{HOMOGENEOUS VS. INHOMOGENEOUS MODELS}

The fundamental nonlinearity in the optimum theory is the self-consistent relation between the flux and the mean profile, adjusted to satisfy the inhomogeneous boundary conditions in $x$. Especially in piasma physics, nosi ather approaches to the transport problem, jncluding particle simulation and analytic schemes, proceed quite differently: 'They assume a fixed but unspecified mean gradient, in terms of which they determine the fux. Which approach is closer to the truth?

The answer we must give is provisional, since our experience with the optimum theory is too recent and incomplete. Ceriainly, in the absence of sourtes the boundary value problem seems closer to physical reality. Of course, diffirulties arise when the governing equations for the region in question embrace a variety of disparate physics and are thus mathematically complicated, and one is led to consider the approaches based on constant mean gradients. However, gradients are constant only if the turbulence is sufficiently local in space. Even if a subregion is excised for analysis, in the absence of sources the mean 
gradients will not be constant linless the correlation length $L_{\mathrm{c}}$ in $x$ is shorter than the width of the subregion. If such an ordering is satisfied, the interior dynamics should be essentially independent of the boundary conditions, and all approaches should be equivalent. In particular, the proper comparison should be between the optimum theor: applied over a region of width $\alpha L_{c}$, where perhaps $\alpha \geqslant 2$, and a statistical closure applied over the same region. No such comparison has yet been done for a realistic situation.

\section{THE FUTURE}

As a technique in its own right, the optimum theory deserves further study, especially for self-consistent situations. We are pursuing some of this work. In particular, we have formulated and are studying a self-consistent optimum theory for collisional drift waves. ${ }^{7}$ The principal complication is that the Euler-Lagrange equations, being three-dimensional and nonlinear, must be solved numerically. However, some analytical work can be done using asymptotic expansions. Some of this analytical and numerical work has been reported. ${ }^{13}$

Less clear is the ultimate role of the optimum theory in the panoply of analytic and numerical approaches to transport. Its rigor is appealing. However, fo- practical applications one often prefers accuracy over rigor: If the true answer is 1 , and if $\epsilon$ is sinall, one would generally prefer $1-\epsilon$ over 10 , though only the latter is an upper bound. Thus, we still feel there is usefu] information to be gained from the family of second-order closures typified by the direct-interaction approximation, which is now becoming computationally accessjble for interesting classes of plasma turbulence. Furthermore, Kraichnan is developing his decimation scheme, ${ }^{14}$ which is at tractive from a number of poinis of view: it unifies amplitude integrations and statistical closures, and it is capable of including information about bounds. ${ }^{15}$ We may expect further progress in this technique, and wish it well. We believe that it is essential to develop as many overlapping approaches to the turbulesce issue as possible, in order to obtain the cross-checks so necessary for a believable scientific theory. Vevertheless, even if the optimum theory is ultimately seen to be a special case of a more unified approach to the problem of turbulence and transport. its present status as the unique rigorous theory for inhornogeneous situations strongly recommends it for further consideration.

\section{ACKNOWLEDGMENT}

This work was supported by U.S.D.o.E. Contract No. DE AC02-76CHO3073. 


\section{REFERENCES}

${ }^{1}$ R. H. Kraichnan, J. Fluid Mech. 5, 497 (1959).

${ }^{2}$ L. N. Howard, J. Fluid Mech. 17, 405 (1975).

3 W. V. R. Malkus, Proc. Rọ: Soc. A 225, 196 (1954).

4 R. H. Busse, Adv. Applied Mech. 18, 7$\rceil$ (1978).

5 "Optimum," implying bounds, should be distinguished from "optimal," a level of pretention which we do not claim. From Websters' New Collegiate Dictionary (Merriam, Springfield, Massachusetts, 1981), we have "optimal ... adj: most desirable or satisfactory"; "optimum ...n.: greatest degree attained or attainable under implied or specified conditions."

${ }^{6}$ J. A. Krommes, C. Oberman, and R. H. Kleva, J. Plasma Ph.s. 30, 11 (1983).

' R. A. Smith. Ph.D. thesis. Princeton University, 1986.

B J. A. Krommes and R. A. Smith, Princeton University Plasma Physics Laboratory Report No. PPPL-2422 (1987); accepted for publication in Ann. Phis. (1987).

9 R. H. Kraichnan, in "Nonlinear Dynamics," edited by H. G. Helleman (New York Academy of Sciences. Jew Jork, 1980), p. 37.

10 P. C. Martin, E. D. Siggia, and H. A. Rose, Phys. Rev. A 8, 423 (1973).

II J. A. Krommes, in "Basic Plasma Physics II," edited by A. A. Galeev and R. N. Sudan (North-Holland, Amsterdam, 1984), chap. 5.5.

${ }^{12}$ S.-K. Chan, Stud. Appl. Math. 50, 13 (1971).

${ }^{13}$ R. Smith and J. A. Krommes, Bul. Am. Phys. Soc. 31, 1360 (1986).

${ }^{14}$ R. H. Kraichnan, in "Theoretical Approaches to Turbulence," edited by D. L. Dwayer, M. Y. Hussaini, and R. G. Voight (Springer, New York, 1985), p. 91.

${ }^{15}$ R. H. Kraichnan, "Some progress in staistical turbulence theory," submitted to "AlAA Progress Series: Proceedings of the Fifth Beer-Sheva International Seminar on MHD Flows and Turbulence," Jerusalem, 1987. 
Dr. Frank J. Paoloni, Unty of wollongong, AUSTRALIA

Prof. M.H. Brennen, Uniy Sydney, AUSTRALIA

Plasma Research Lab., Australian Mat. Univ., AUSTRALIA

Prof. I,R. Jones, FIlinders UnIV., AUSTRALIA

iraf. $r$. Cad, Inst Theo Phys, NuSTRIA

Prot. M. Helndior, I nstitut fur Theoretische Physlk, AUSTRIA

A. Goossens, Astronomisen Instituut, BELGIUM

Ecolo hayol MIIItelrs, Lab de Phys Plasmas, BELGILM

Com. of European, Dg Xil Fusion Prog, BELGIUN

Prot. R. Bouclque, Labortatoriun voor Natuurkunda, gELGILM

Or. P.H. Sakanaka, Uní Estadual, BRAZIL

Instituto De Posquisas Especiasi-IRPE, BRAZI L

Library, Atomle Energy of Canade Cinlted, CANAOA

Or. M.P. Bechynskl, MPB Tachnologias, Inc., CNAOA

Or. H.H. Skarsgard, Unlv of Saskatchewan, CANAOA

Or. H. Barnord. Unlvorsity of British Columbia, CANeOA

Prof. J. Talchmann, Unlw, of Hentreal, CAMADA

Prot. S.R. SreenIveson, Univarsity of Calgary, CANADA

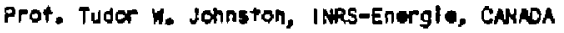

Dr. C.R. Jomes, UnIV, of AiberTE, CNNOA

Or. Poter Lukec, Komonłkeno UnIV, CZECHOSLOYAKIA

The Librarian, Culha Leboratory, EHGLANO

Mrs. S.A. HutehInson, JET LIbrary, EHGLANO

C. Hutter, Lob, de Physique des Milleux Ionlsés, fRNACE

J. Radot, CEH/CADARACHE - Bat 506, FRAHCE

Dr. Ton thual, Acadany albliogrophle, HONG KONG

Preprint LIbrary, Cont Ros Inst Pnys, HUNGARY

Dr. B. Dasgupta, Saha Inst, IMDIA

Dr. R.K. Chhajlani, Vikran UnlY. INDIA

Or. P. Kow, Instltute for Plasena Researen, INOIA

Or. Philllo Rosenal, I siael Inst Tech, ISRAE!

Prot. 5. Cupeman, Tol Ariv University, ISRAEL

Llbrarlan, Int'l Ctr Theo Phys, ITALY

Prof. G. Rostagni, Unir ol Fadove, ITALr

Miss Clella de Palo, Assoc EURATOH-ENEA, ITALY

labllotece, del OR EURATOM, ITAY

Dr. H. Yanato, Toshlba Aces \& Dev, JAPAN

Prof. I. Kawakaml, Atcalc Energy Res. Institute, JAPAN

Prof. KYojI NIshIkame, Univ af HIroshima, JAPN

Direc. Dept, Lg. Tokariak Res. JAERI, JAPAN

Prot. Satoshi Itoh, Kyushu Univors ity. JNPN

Rosearch into Conter, Magoys ynivarsity, JNPN

Prot. S. Tanaka, Kyoto University, JAPAN

LI brary, Kyato Univarslity, JAPAN

Prot, Nobuyuki Inoue, Unlversity of Tokyo, JAPNY

S. Mori, JAERI, JAPAN

M.H. KIm, Kores Advaneed Energy Roseareh Instltute, KOREA

Praf. 0.1. Chol, Adv, Inst Sel \$ T\&h, KOREA

Prat. B.S. LIley, Uniyarsity of Walkato, NEW 2ENAND

Institute of Plasm Physlcs, PEOPLE'S RePUELIC OF CHINA

Cibrarian, ingtitute of Phys., PEOPLE'S REPULIC OF CHINA

LIbrary. Tsing Hua University, PEOPLE'S REPUBLIC Of CHIMA
2. LI, Southwest Inst. Physles, PEOPLE'S REPUBL IC OF CHINA Prof, J.A.C. Cabral, Inst Supertor Teen, PORTUGAL Dr. Uctarlan Patrus, AL I CUZA Unlvarsity, ROManis Dr. Johan de Vilillors, Plasma Physics, AEC, SO AFRICA Prof. M.h. Mollberg, Unlverstty of Natal, SC AFRICA Fus con Olu. Glorary, JEN, SPAIN

Dr. Lonnart Stenflo, Univorsity of UMEA, SWEDEN

Librery, Royal Inst Tenth, SwEDEN

Prot. Hans Wliholmson, Chalmers Univ Tach, SWEDEN

Centio Phys des Plasmas, Ecolo Polytech Fod, SWITZERLAND Blbllathaek, Fom-Inst Voor PIasma-Fyslea, THE NETHERLANDS Or. O.0. Ryutov, SIbarlan Acod Scl, USSR

Dr. G.A. Ellseev, Kurchatar InstItute, USSR

ar. l.A. Giukhlkh, Inst Electro-Physical, USSR

Or. V.T. Tolok, Inst, Phys, Toch. USSR

Or. L.M. Kovrlzhnykh, Institure Gush, Physles, USSR

Prof. T.J.H. Boyd, Ur.l Colloge $N$ Wales, WALES

Nuclear Ros. Establishmant, Julleh Ltd., W. GERMANY

Blbliothak, Inst. Fur Plasmafarschung, W. GERMANY

Dr. K. Sehindler, Rühr Unlversitat, W. GERMANY

ASOX Rending Rn, IPP/Max-Planck-Institut fü

Plasmaphysik, H. GEPANY

LIbrarlan, wax-Planck Instltut, W. GERMAYY

Prof. R.K. Jarew, 1nst Phys, Yugoslavia 